\title{
HEALTHCARE WASTE MANAGEMENT: A CASE STUDY OF HEALTH-PROMOTING HOSPITALS
}

\author{
SINEENART PUANGMANEE \& MOLTIYA JEARANAI \\ Environmental Science, Faculty of Science and Technology, Phuket Rajabhat University, Thailand
}

\begin{abstract}
Healthcare waste management from health-promoting hospitals in some local areas of Thailand is weakly regulated. Pollution from the waste originates from poor management, ineffective control, and unsuitable disposal. We reviewed the management of healthcare waste at health-promoting hospitals and aimed to study the type and quantity of healthcare waste, storage, collection, transfer, transportation and disposal. Six hospitals were selected and prioritized from a district in a province in the upper part of southern Thailand. All waste was classified into two types: waste from treated patients (general waste, hazardous and infectious waste) and waste from untreated patients (domestic and hazardous waste). The highest percentage of waste from treated patients was $68.20 \%$ and waste from untreated patients was $86.60 \%$. The waste from treated patients at all hospitals was put into red plastic bags and placed inside stainless steel or plastic garbage cans. The waste materials were then transferred daily by hospital employees. They wore protective equipment while working. The waste from untreated patients was put into black plastic bags and placed inside plastic or stainless steel garbage cans. The waste materials were transferred the same way as the waste from treated patients. Waste from the treated patients was then transported by a hospital employee who wore unsuitable protective equipment. The waste materials were collected from all health-promoting hospitals once a week by pickup truck and moved to a single hospital in the district where it waited for transportation to an incineration plant in central Thailand. The waste from untreated patients was transported by employees of the sub-district administrative organization. They also wore unsuitable protective equipment while working. The waste from untreated patients was transported by compact garbage truck and moved for disposal in two open dump sites in the local area. Although the waste materials were basically controlled and managed by the guidelines, some of the handling processes were incorrect and ineffective. Therefore, everyone involved in healthcare waste management from the top down need to strictly practice the guidelines according to the laws for a better environment.
\end{abstract}

Keywords: healthcare waste, healthcare waste management, health-promoting hospitals.

\section{INTRODUCTION}

Healthcare waste $(\mathrm{HCW})$ is different from other waste products (municipal/industrial and agriculture waste) because it is produced by healthcare establishments. Healthcare facilities (HCF) consist of government hospitals, private hospitals, private clinics, laboratories, medical centers, [1] and primary health centers [2], and they have many sources of HCW. The sources of HCW are from diagnostic procedures of treated and untreated patients. The composition of most HCW includes healthcare general waste that is similar to domestic waste (non-hazardous waste) at around $75-90 \%$, and hazardous waste and infectious waste amount to about $10-25 \%$ that is called healthcare risk waste (HCRW) [3], [4]. If HCRW, especially infectious waste, is poorly managed through the stages of segregation, storage, collection, transfer, transport, and disposal, it can affect the environment and public health. Generally, large HCFs always have HCW management policies because they are regulated by law, but some HCFs have poor management, especially the small HCFs such as the primary health centers. In Thailand, a primary health center is a small local healthcare facility which is referred to as a health-promoting hospital (HPH) that serves a population of around 1,000 5,000 inhabitants in a village or district [5]. The treatment services at a HPH are basic services on an out-patient basis only and include medical treatment, health promotion, disease 
prevention, and rehabilitation [5]. Since the treatment services are comprehensive, HCW can be produced by both treated and untreated people and by other activities in the HPHs which are sources of hospital pollution. The amounts of waste depend on the number of people that receive the services and do other activities. The types of waste materials include general waste, hazardous waste, and infectious waste. In addition, it was found that some HPHs have poor treatment and disposal system management and incorrect management according to the guidelines. If the management and control are ineffective, the produced waste residues may find their way into the environment with the possible distribution of pathogens and chemical hazards. Thus, this research aimed to study the types, amounts, storage and collection facilities, transfer and transport, and the disposal of HCW from HPHs based on prioritizing 6 out of 12 HPHs in the district of a province in the upper part of southern Thailand.

\section{METHODOLOGY}

This paper is a survey research that focuses on the management of healthcare waste from HPHs that are local healthcare facilities in one district of a province in the upper part of southern Thailand. All of them are regulated by the Ministry of Public Health of the government of Thailand.

\subsection{Measurement sites}

Six HPHs were selected from $12 \mathrm{HPHs}$ in the district of a province in the upper part of southern Thailand. The 6 HPHs were then prioritized from the largest to the smallest number of people served. The HPHs were coded (A-F) to protect their identity. The study was conducted between June and August 2017.

\subsection{Methods}

\subsubsection{Surveys and interviews}

Surveys and interviews were conducted with the employees responsible for the handling of $\mathrm{HCW}$ to study the type and quantity of $\mathrm{HCW}$ and the storage and collection of waste in terms of the containers, employees, and equipment. Also studied were the transfer, transport, and disposal in terms of employee, period of time for transfer/transport, equipment, vehicle, and disposal site. In our study, an employee in each HPH refers to a delegate who managed the $\mathrm{HCW}$. The total number of interviewed employees was 8 in 3 areas of responsibility. The first area of responsibility consisted of 6 professional registered nurses who controlled and managed the waste at each of the 6 HPHs. The second area of responsibility was a delegate from the 12 HPHs. This employee was an experienced technical nurse. The last person was a representative from a district hospital who was responsible for infectious control. This employee managed and controlled the infectious waste from all $12 \mathrm{HPHs}$.

\subsubsection{Samplings}

The types and quantity of HCW were studied by sort segregation and the HCW was weighed once a week in two types of HCW at each HPH. The HCW consisted of waste from treated patients (HCW-TP) and healthcare waste from untreated patients (HCW-UTP).

\section{RESULTS AND DISCUSSION}

The results of this paper were an overall image of healthcare management from six HPHs that describe the activities, types, quantities, storage, collection, transfer/transport, and disposal of HCW. 


\subsection{Activities}

The activity services at all six HPHs (A-F) were of four types and the activities were similar at each HPH. Services at each HPH included antenatal care, vaccination, family planning, and a non-communicable disease clinic that included a hypertension clinic and diabetes clinic (Table 1).

\subsection{Types and quantities}

The types and quantities of HCW in the 6 prioritized HPHs were categorized into two types: $\mathrm{HCW}$ from the HCW-UTP and HCW from the HCW-TP. At most HPHs (5/6) the percentage of HCW-UTP was greater than HCW-TP (Fig. 1). This was in agreement with a report by Chartier et al. [4]. Overall, the kinds of HCW-UTP at all HPHs consisted of domestic waste and hazardous waste that was not a result of treating patients (Fig. 2). The sources of these materials were from office!buildings. The domestic waste materials included paper, plastic containers, and plastic bags. Hazardous waste included aerosol spray cans, batteries, desiccants, electric light bulbs, fluorescent lamps, and glue.

The rates of domestic and hazardous waste based on the average amount per person from all HPHs were $0.04-1.30$ and $0.11 \mathrm{~kg} /$ person/day, respectively. HCW-TP included three types which were general waste, hazardous, and infectious waste (Fig. 3).

Most of the general waste materials included packages and wrappings of medical supplies and other equipment that were unpacked and unwrapped before being used in treated patients. In addition, hazardous wastes included expired drugs (liquid and pill/capsule drug), sharp object waste (uninfected), broken equipment (clinical thermometers), but did not cover used infectious medical supplies. Finally, infectious waste materials were found in all waste and contaminated with!pathogens. All of these waste materials were similar to the report by Nemathaga concerning hospital solid waste management in South Africa [6]. The rates of general waste, hazardous waste, and infectious waste based on the average amount per person from all HPHs were $0.01,0.07$, and $0.02-0.09 \mathrm{~kg} /$ person/day, respectively.

Table 1: The activity services at all health-promoting hospitals (HPHs: A-F).

\begin{tabular}{|l|c|c|c|c|}
\hline \multirow{2}{*}{ Activity service } & \multicolumn{3}{|c|}{ Time of service in each HPH } \\
\cline { 2 - 5 } & $\begin{array}{c}\text { Every } \\
\text { Tuesday }\end{array}$ & $\begin{array}{c}\text { Every 2nd } \\
\text { Wednesday } \\
\text { of the month }\end{array}$ & $\begin{array}{c}\text { Every 3rd } \\
\text { Wednesday } \\
\text { of the month }\end{array}$ & $\begin{array}{c}\text { Every } \\
\text { Thursday }\end{array}$ \\
\hline Antenatal care & & & $\begin{array}{c}\text { Every } \\
\text { hospital }\end{array}$ \\
\hline Vaccination & & $\begin{array}{c}\text { Every } \\
\text { hospital }\end{array}$ & D, C, F & \\
\hline Family planning & $\begin{array}{c}\text { Every } \\
\text { hospital }\end{array}$ & & & \\
\hline $\begin{array}{l}\text { Non-communicable disease clinic } \\
\text { Hypertension clinic } \\
\text { Diabetes clinic }\end{array}$ & \multicolumn{3}{|c|}{ Depended on plan of hospital worker } \\
\hline
\end{tabular}



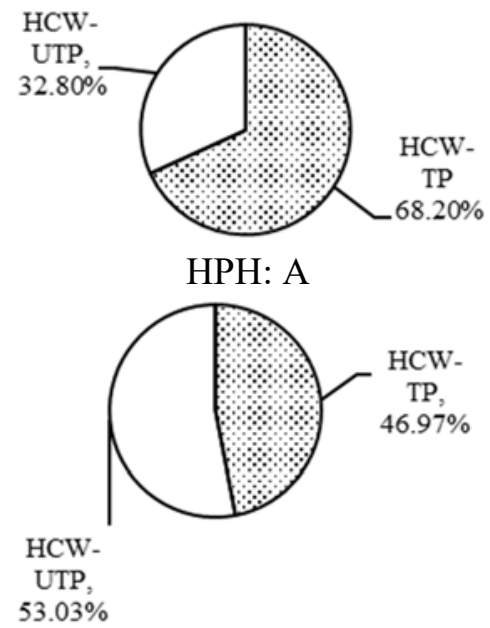

HPH: C

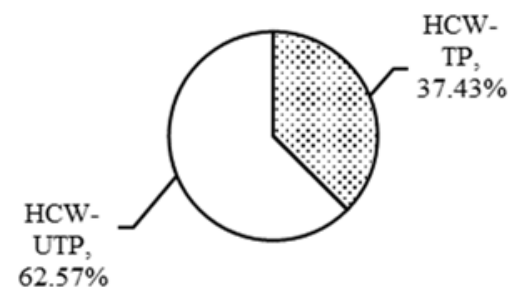

HPH: E

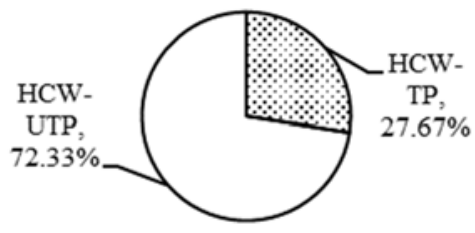

HPH: B

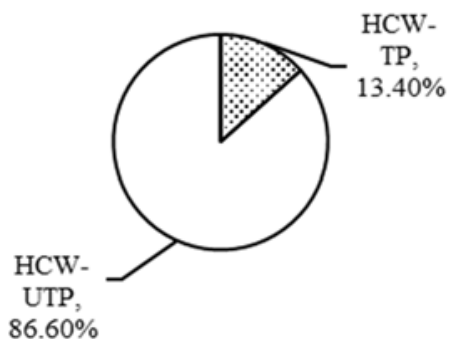

HPH: D

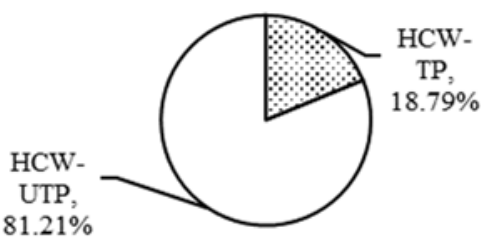

HPH: F

Figure 1: Types and percentages of HCW at six HPHs. (Source: Puangmanee and Jearani [13].)

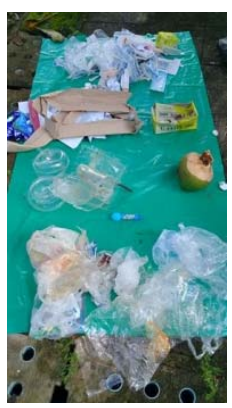

(a)

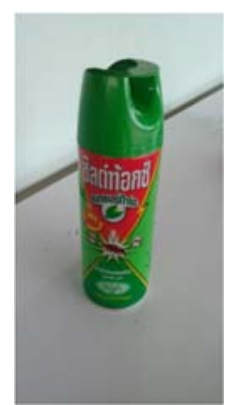

(b)

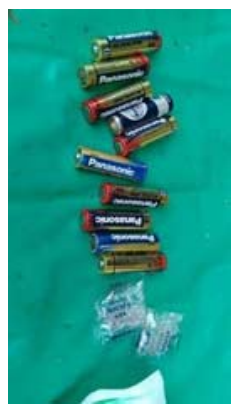

(c)

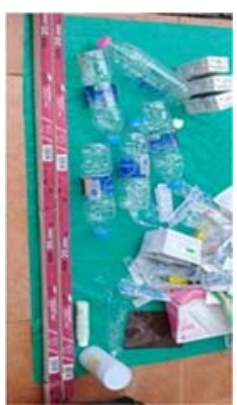

(d)

Figure 2: Examples of HCW-UTP. (a) Domestic waste; (b)-(d) Hazardous waste. 


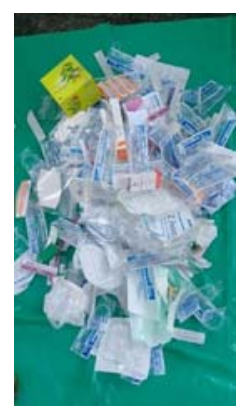

(a)

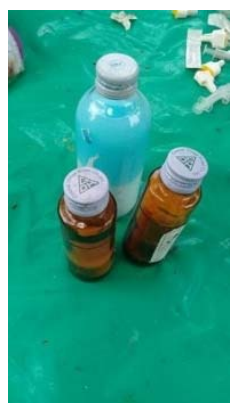

(b)

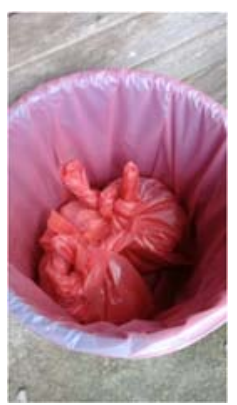

(c)

Figure 3: Examples of HCW-TP. (a) General waste; (b) Hazardous waste; (c) Infectious waste.

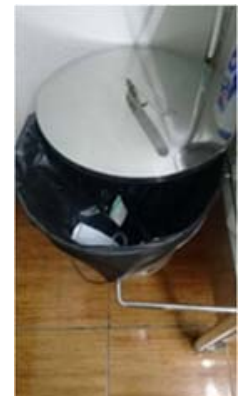

(a)

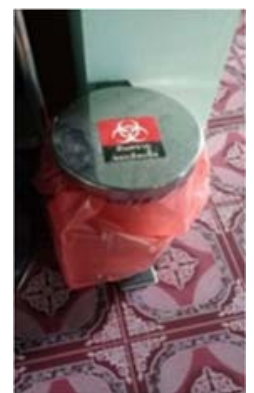

(b)

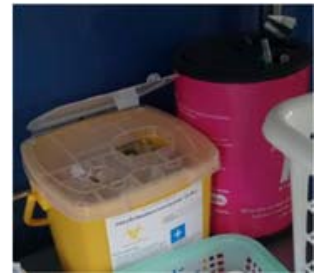

(c)

Figure 4: Containers of HCW-TP. (a) Garbage can for general waste; (b) Garbage can for infectious waste; (c) Sharp objects bin.

\subsection{Storage and collection}

Storage and collection of HCW at all HPHs were separated into HCW-UTP and HCW-TP (Fig. 4).

The storage and collection of unseparated general waste from HCW-TP was collected into black plastic bags and placed into plastic or stainless steel garbage cans which was similar to a report by Diaz et al. [7]. The part of HCW-TP that could be classified into hazardous waste (expired drugs or pharmaceutical waste) was separated from other waste at all HPHs and kept in a basket. The infectious waste was kept in red plastic bags and placed inside stainless steel or plastic garbage cans. In some countries yellow bags are used to keep infectious waste which requires special management of pathological, infectious, sharp objects, microbiology, and human anatomical waste [7], [11]. All garbage cans were covered with a lid. The garbage cans were in accordance with a report by Senawang [8] that described the containers for HCW-TP from HPHs which used stainless steel and plastic garbage cans. Otherwise, sharp objects were collected in a sharp objects bin which had a hole at the top for placing sharp objects into the bin that had no bag. The nearly expired drugs at the HPHs were transferred to other HPHs to reduce the volume of discarded drugs that needed to be returned to the 


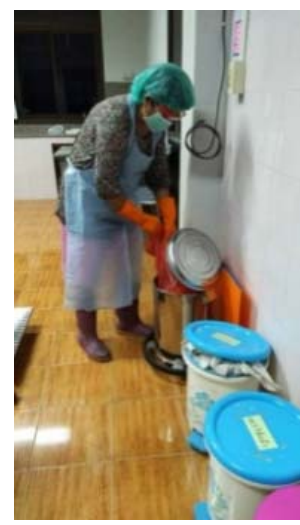

Figure 5: Protective equipment suit of employee.

supplier. Infectious waste was collected and moved to an infectious waste center inside each $\mathrm{HPH}$ daily by employees. The employees or waste workers wore personal protective equipment while working (Fig. 5).

The personal protective equipment of the employees consisted of health mask (face mask), gloves (rubber/household gloves or heavy-duty gloves [4]), medical cap, eye goggles, plastic apron, and rubber boots/shoes (industrial boots). In the case of HCW-UTP, the domestic waste from untreated patients such as paper, plastic glass, and plastic bags were mixed with compostable waste (food, fruits, and vegetables) and put into a black plastic bag and placed inside a plastic garbage can (Fig. 6).

The hazardous waste materials were kept and mixed into the domestic waste garbage can without separation. These waste materials were removed daily to a domestic waste center inside the HPH by employees or waste workers but they wore unsuitable personal protective equipment. Some parts of the important sources of HCW-UTP were from the relatives of patients who came into the HPH but they were untreated or they were untreated patients who came into the HPHs to receive only drugs. The composition of the waste was similar to a report by Saengbunrung [9] who reported on the quantity and composition of HCW-UTP in a hospital that was found to consist of $46 \%$ compostable and domestic waste. Otherwise, HCW-UTP was found from other activities unrelated to treated patients.

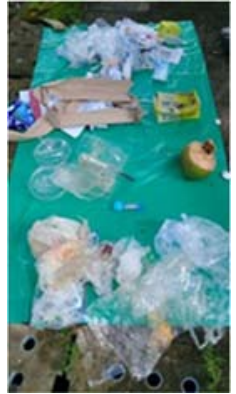

(a)

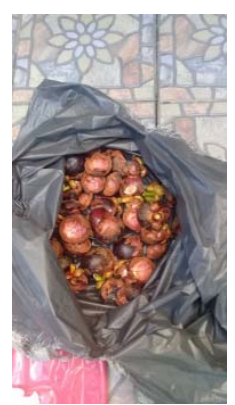

(b)

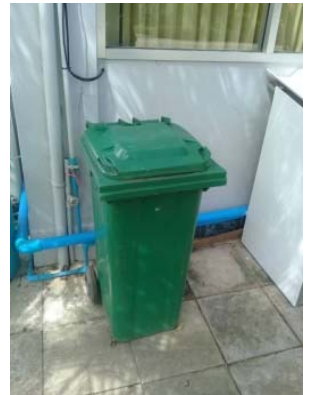

(c)

Figure 6: HCW-UTP. (a) Domestic waste; (b) Compostable waste; (c) Garbage can for domestic waste. 


\subsection{Transfer/transport and disposal}

The HCW-TP, especially hazardous waste and infectious waste, was collected and transferred to a district hospital by a hospital employee once a week, but while working wore unsuitable protective equipment that was in conflict with the Ministerial Regulation on the Disposal of Infectious Waste B.E. 2545 (2002) [12]. The employees wore just one glove and the shoes were not rubber or industrial boots (Fig. 7). In addition, each HPH used a pickup truck to take the waste materials to a district hospital where it waited for transportation for disposal at an incineration plant in central Thailand.

The unsuitable hazardous and infectious waste collection and transfer conflicted with the Ministerial Regulation on the Disposal of Infectious Waste B.E. 2545 (2002). The personal protection equipment of the employee must include a health mask (face mask), gloves (rubber/household gloves or heavy-duty gloves), medical cap, eye goggles, plastic apron, and rubber boots (industrial boots). The vehicle must have an unencumbered structure, inner wall made from durable material, easy to clean, and no leakage. The general waste from the treated patients was collected with the domestic waste which was similar to a report by Patil and Shekdar [11] that described healthcare waste management in India where non-infectious waste was mixed with municipal solid waste for disposal and the hazardous waste from untreated patients was not classified. The collection was waste materials was conducted by employees of the sub-district administration organization, but while working they wore unsuitable protective equipment. They wore only one glove and regular shoes (not boots) which conflicted with the Ministerial Regulation on General Waste Management B.E. 2560 (2017) [10]. The waste products were transported by compact garbage truck (Fig. 8) and moved for disposal to two open dump sites in the local area (Fig. 9).

Finally, the pathway of healthcare waste in this research is shown in the route map in Fig. 10.

The pathway of healthcare waste management starts from the sources to the end at all HPHs is regulated by law and under government control. However, some parts are ineffectively managed. For example, the HCW-UTP needs to be disposed at a sanitary landfill, but it is not. Open dumps are used for the disposal of HCW-UTP. Some HPHs do not segregate the waste between hazardous waste (batteries and lamps) and domestic waste or compostable waste is not separated from domestic waste (paper, plastic bottles, plastic glass, and plastic bags) in HCW-UTP. In addition, the employees or waste workers wear unsuitable personal protective equipment while working inside the building and during

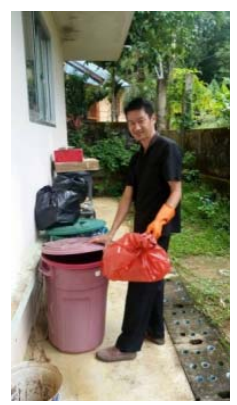

(a)

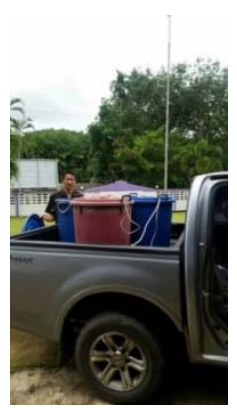

(b)

Figure 7: (a) Unsuitable personal protective equipment and collection; (b) Unsuitable transfer. (Source: Puangmanee and Jearani [13].) 


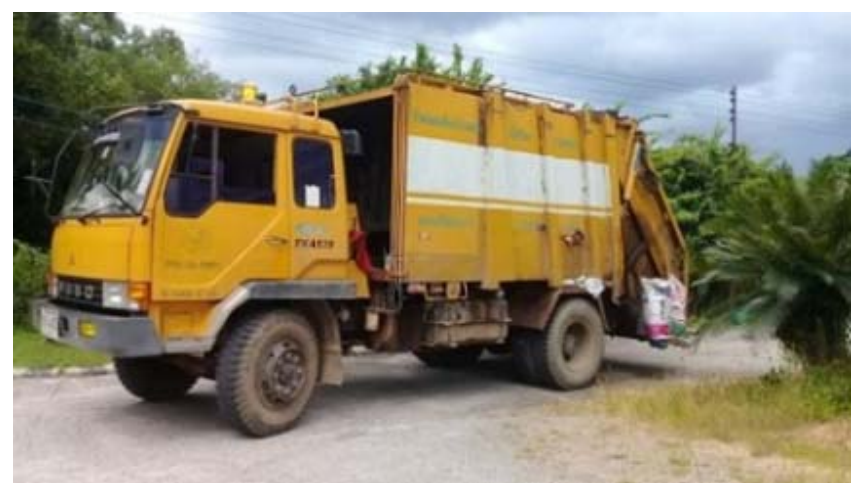

Figure 8: Compact garbage truck.

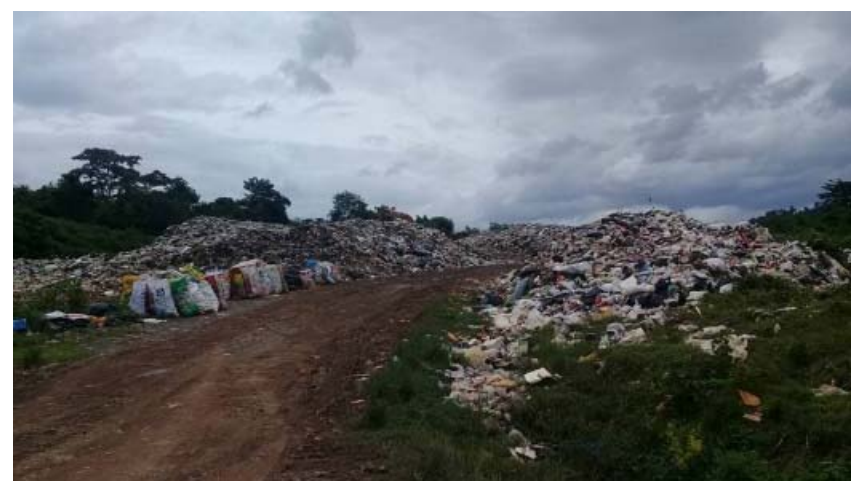

Figure 9: Open dump.

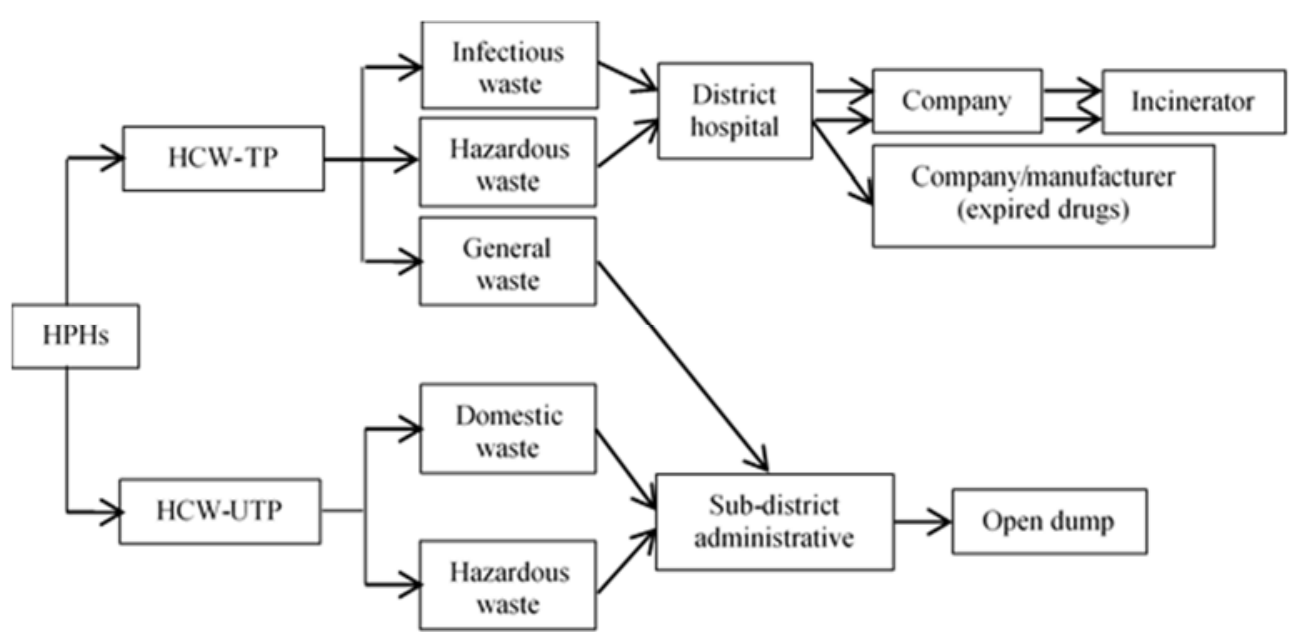

Figure 10: Route map of healthcare waste. 
transfer/transport of the waste materials for disposal outside of the HPHs. Furthermore, the vehicles used to carry the infectious waste materials do not follow the standard set by law. In addition, the HPHs need to have strict compliance concerning the infectious waste management system concerning personal protective equipment, vehicles, and other requirements for the management of $\mathrm{HCW}$ at all $\mathrm{HPHs}$.

\section{CONCLUSIONS}

The healthcare waste in health-prompting hospitals can be separated in two types which are healthcare waste from untreated patients (domestic and hazardous waste) and treated patients (general waste, hazardous waste and infectious waste). The main sources of waste materials were from treated patients in four service activities (antenatal care, vaccination, family planning, and non-communicable disease clinic (hypertension clinic and diabetes clinic), and untreated patients from the office buildings. The proportion of waste from untreated patients was more than the treated patients. The containers for storage and collection of all waste materials (bags, color of bags, and garbage cans) for HCW-TP and HCW-UTP were used correctly. However, the personal protective equipment of the waste workers who handled infectious waste while working was incorrect. Furthermore, unsuitable clothing and vehicles were used in the transfer/transport of infectious waste which was in conflict with the guidelines. Finally, the practice of using an open dump for the disposal of HCW-UTP is unlawful according to the laws of Thailand. We conclude it is necessary that the healthpromoting hospitals strictly practice the guidelines and comply with the standards set out by law to properly handle and dispose of all waste materials to reduce the effects of healthcare waste pollution on the environment.

\section{ACKNOWLEDGEMENT}

The authors would like to thank Phuket Rajabhat University for their financial support for the registration and carfare.

\section{REFERENCES}

[1] Prem Ananth, A., Prashanthini, V. \& Visvanathan, C., Healthcare waste management in Asia. Healthcare waste management in Asia. Waste Management, 30(1), pp. 154161, 2010. DOI: 10.1016/j.wasman.2009.07.018.

[2] Kafle, H., Hospital Waste Management. Online. www.slideshare.net/ harikafle944/hospital-waste-management-47700029. Accessed on: 12 Jun. 2018.

[3] Types of HCW: Proportion and Hazard. Online. www.healthcare-waste.org/ basics/definitions/. Accessed on: 12 Jun. 2018.

[4] Chartier, Y. et al., Safe management of wastes from health-care activities. Online. http://apps.who.int/iris/bitstream/handle/10665/85349/9789241548564_eng.pdf;jsess ionid=A74F6584BC09D92A5ADF7CF5FB36A386? sequence=1. Accessed on: 12 Jun. 2018.

[5] Elevate health center to health promotion hospitals, Thai Health Promotion Foundation. Online. www.thaihealth.or.th. Accessed on: 14 Jun. 2018.

[6] Nemathaga, F., Maringa, S. \& Chimuka, L., Hospital solid waste management practices in Limpopo Province, South Africa: A case study of two hospitals. Waste Management, 28, pp. 1236-1245, 2008.

[7] Diaz, L.F., Eggerth, L.L., Enkhtsetseg, Sh. \& Savage, G.M., Characteristic of healthcare wastes. Waste Management, 28, pp. 1219-1226, 2008. 
[8] Senawang, L., Infectious waste management of tambon health promoting hospital in Namon district, Kalasin province. Research and Development Health System Journal, 6(3), pp. 163-170, 2014.

[9] Saengbunrung, S., Waste management in Maharat Nakhon Rachasima hospital. Maharat Nakhonrat Ratchasima Hospital Medical Bulletin, 33(2), pp. 105-109, 2009.

[10] Ministerial Regulation General Waste management B.E. 2560 (2017). Online. http://laws.anamai.moph.go.th/main.php?filename=2RLaws. Accessed on: 14 Jun. 2018.

[11] Patil, A.D. \& Shekdar, A.V., Health-care waste management in India. Journal of Environmental Management, 63, pp. 211-220, 2001.

[12] Ministerial Regulation Disposal of Infectious B.E. 2545. Online. http://laws.anamai.moph.go.th/main.php?filename=2RLaws. Accessed on: 14 Jun. 2018, 2002.

[13] Puangmanee, S. \& Jearani, M., Solid waste management from a primary care unit. Proceedings of the 7th National Conference, pp. 19-20, 2018. 